\title{
Marxismo, política y universidad, o la experiencia de la revista Dialéctica (1976- 2015). Entrevista a Gabriel Vargas Lozano
}

\author{
Marxism, politics and university, or the experience of the Dialéctica journal (1976-2015). Interview \\ with Gabriel Vargas Lozano
}

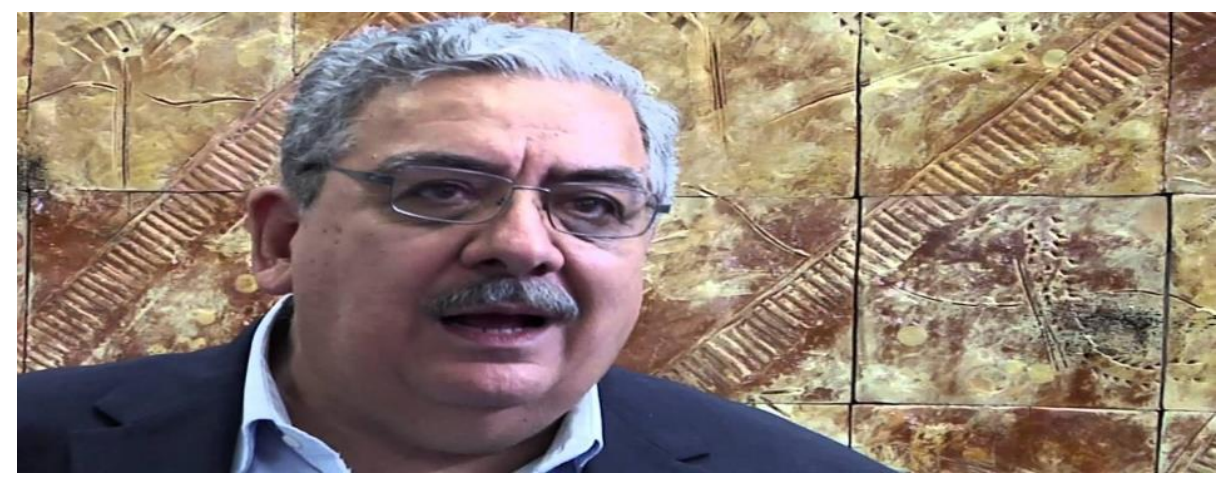

Diego Martín Giller*

El objetivo de esta entrevista es reconstruir y repensar una de las experiencias más significativas del universo de revistas político-culturales de las izquierdas latinoamericanas en general, y de las mexicanas en particular: la revista Dialéctica (1976-2015). Junto a su principal animador, Gabriel Vargas Lozano, repasamos sus orígenes y sus búsquedas, sus relaciones con la universidad y la política, la teoría marxista, el Partido Comunista Mexicano (PCM) y los exiliados latinoamericanos en México. Asimismo, se busca reflexionar sobre las dificultades que supone editar una revista de teoría política marxista, autoubicada en los márgenes de la industria académica que domina nuestros días.

The objective of this interview is to rebuild and to think over one of the most important experience of the universe of political and cultural revue of the Latin-American left in general, and the Mexican's in particular: the revue Dialéctica (1976 - 2015). We are going to review along with Gabriel Vargas Lozano, the main host of the revue, the background and the research, the relations with the university and the politics, the Marxist theory, the Communist Party of Mexico (PCM) and the Latin American exiles in Mexico. Likewise, we will think about the difficulties that editing a revue of Marxist political theory means, autolocated in the edges of the academic's industries wich command nowadays.

\footnotetext{
* Argentino. Doctor en Ciencias Sociales, Magister en Investigación en Ciencias Sociales y Licenciado en Sociología, todos por la Universidad de Buenos Aires. Becario postdoctoral en el Instituto del Desarrollo Humano de la Universidad Nacional de General Sarmiento (IDH-UNGS). Correo electrónico: diegogiller@gmail.com
} 
2 de octubre de 1968. La que aparentaba ser sólo una jornada más de lucha en el marco de un almanaque concebido bajo la égida de un tiempo lineal, homogéneo y vacío, según la ya célebre definición de Walter Benjamin ${ }^{1}$, terminó siendo un verdadero parteaguas en la historia política mexicana en general, y en sus izquierdas en particular. Es que ese trágico día se fraguó la llamada "Masacre de Tlatelolco", perpetuada contra el poderoso movimiento popularestudiantil que había dicho presente en los meses inmediatamente previos. A partir de entonces, el mapa de las izquierdas comenzó a ampliarse y diversificarse ${ }^{2}$, dejando al campo intelectual sin espacio para las dudas: ser intelectual significaba adoptar posturas y lenguajes de izquierdas.

Uno de los grandes protagonistas de esa conjura fue el marxismo. Rápidamente transformado en lengua de la época, llenó los catálogos de importantes y reconocidas casas editoriales (ERA, Grijalbo, Siglo XXI, Joaquín Mortiz, etc.) y devino enseñanza obligatoria de las principales carreras universitarias. Este escenario se extendió y profundizó cuando México ofició como país receptor de miles de exiliados latinoamericanos que huían de las dictaduras que, como efecto dominó, se instalaban a lo largo y ancho de nuestra región.

Las revistas político-culturales fueron uno de los productos más representativos del período histórico abierto aquel día, a tal punto que los años posteriores pueden ser narrados a través de ellas. Páginas como las de Punto Crítico ${ }^{3}$, Historia

\footnotetext{
1 Benjamin, Walter, Sobre el concepto de historia, Buenos Aires, Piedras de Papel, 2007.

2 Carr, Barry, La izquierda mexicana a través del siglo XX, México, ERA, 1996.

3 Punto Crítico fue fundada en 1972 por algunos dirigentes del movimiento popular-estudiantil de 1968: Gilberto Guevara Niebla, Raúl Álvarez Garín, Roberto Escudero, Eduardo Valle y Salvador Martínez de la Rocca. También participaron otras figuras de la intelectualidad de izquierdas como Adolfo Sánchez Rebolledo, Carlos Pereyra y Rolando Cordera. El movimiento obrero y campesino, los colonos, la guerrilla, los cristianos de izquierda, el incipiente movimiento feminista -del cual se publicaron los primeros documentos-, el problema de la ecología, la salud en el trabajo, y sobre todo, la democracia sindical ocuparon un
}

y Sociedad ${ }^{4}$, Cuadernos Políticos ${ }^{5}$, Fem. ${ }^{6}$, Coyoacán $^{7}$, Nexos $^{8}$, El Machete ${ }^{9}$ o Memoria ${ }^{10}$

lugar destacado en la revista. Para una profundización ver Sánchez Rebolledo, Adolfo, "Pensar el 68. Punto Crítico: Una historia de familia. Entrevista Con Adolfo Sánchez Rebolledo", Nexos, junio 1988; Bayle, Mariana, "'Revistas en combate'. Cultura, política y rupturas en la nueva izquierda mexicana (1968-1875)', Cuadernos del CEL, Vol. II, Núm. 4, 2017, pp. 27-43.

4 Historia y Sociedad fue una revista de debate político intelectual que se movió en el espectro ideológico del comunismo mexicano. Bajo la dirección de Enrique Semo, y con el subtítulo de "Revista continental de humanismo moderno", la primera época de la revista se desplegó entre 1965 y 1970, publicando 16 números. Los 24 números de la segunda época salieron entre 1974 y 1981, también con dirección de Semo, pero ahora acompañado de Roger Bartra. Las publicaciones de esta segunda época, en la que el viejo subtítulo cedía su lugar al de "Revista latinoamericana de pensamiento marxista", privilegiaron el problema de la articulación de modos de producción en sociedades periféricas, la transición al socialismo, el desarrollo del capitalismo en México, la crítica de la teoría de la dependencia, la cuestión agraria y las revoluciones burguesas en América Latina.Para una profundización recomendamos Illades, Carlos, "Historia y sociedad", La inteligencia rebelde. La izquierda en el debate público en México. 1968-1989. México, Océano, 2012, pp. 49-72.

${ }^{5}$ Editada por la editorial ERA, Cuadernos Políticos publicó 60 números de manera ininterrumpida, entre 1974 y 1990. Neus Espresate, Arnaldo Córdova, Rolando Cordera y Adolfo Sánchez Vázquez conformaron el primer consejo editorial. Años después se sumarían Ruy Mauro Marini y Bolívar Echeverría. Sus temas de interés giraron en torno a las dictaduras del cono sur, el proceso revolucionario en Centroamérica, las teorías de la dependencia, el imperialismo, la lucha de clases, las formaciones económicosociales, el movimiento estudiantil, el Estado, la cultura, la crisis del capitalismo y las relaciones entre socialismo y democracia. Para una profundización ver Illades, Carlos, op. cit., pp. 89-114; Bayle, Mariana, "Arnaldo Córdova sobre la izquierda en los setenta", Nexos, 9 de febrero de 2015; y Bayle, Mariana, "'México como escenario latinoamericano. Dictadura, revolución y democracia en las revistas Cuadernos Políticos (1974-1999)", Cuadernos del CEL, Vol. II, Núm. 3, 2017, pp. 300-314.

${ }^{6}$ Revista pionera del movimiento feminista mexicano, Fem. había sido fundada por Alaíde Foppa y Margarita García Flores en 1976. Formaban parte del consejo editorial Elena Poniatowska, Lourdes Arizpe, Margarita Peña, Beth Miller, Elena Urrutia, Marta Lamas y Carmen Lugo. Con el objetivo de vincular la lucha de las mujeres con la lucha de los oprimidos, su centro de interés fue la acción política del movimiento feminista. Se publicaron artículos sobre el aborto, el trabajo doméstico, la religión y la participación de 
las mujeres en la política. Para una profundización ver García Vázquez, Xóchitl, "FEM, una mirada crítica al feminismo", Latinoamericano, Revista digital, número 6, marzo 2014 pp. 36-40.

7 Dirigida por Adolfo Gilly, Coyoacán. Revista marxista latinoamericana fue una revista independiente de orientación trotskista. Publicada por la editorial El Caballito entre 1977 y 1985, sacó 18 números de manera trimestral. En su consejo de redacción se enredaban intelectuales de Europa y América Latina: Guillermo Almeyra, Alberto Pla, Jorge Dauder, Michael Löwy, Alberto Di Franco, Roberto Iriarte, Rodolfo Peña, Arturo Anguiano, Oscar René Vargas, C. D. Estrada y Gilberto Mathias. Bajo la ideología del marxismo revolucionario buscaba interpelar a la clase obrera, la vanguardia campesina y los intelectuales revolucionarios de América Latina y España. Prestó especial atención a los procesos revolucionarios en curso (sobre todo la revolución sandinista y la geografía centroamericana), la lucha contra las dictaduras de Sudamérica, el espacio andino, las huelgas obreras en Brasil, Colombia, Perú y México, el movimiento sindical, el movimiento polaco de Solidaridad y el proletariado español. Ver Illades, op. cit.

8 Animada por algunos voceros del movimiento estudiantil de 1968, Nexos comenzó a publicarse en enero de 1978. Había surgido de unos encuentros sabatinos de los que participaban diversas figuras de la intelectualidad mexicana: Guillermo Bonfil Batalla, Víctor Flores Olea, Adolfo Gilly, Pablo González Casanova, Lorenzo Meyer, Yolanda Moreno Rivas, Alejandra Moreno Toscano, Carlos Monsiváis, José Emilio Pacheco, Carlos Pereyra, José Luis Reyna, Luis Villoro y Arturo Warman. Enrique Florescano fue su primer director y Héctor Aguilar Camín, Adolfo Castañón y Julio Frenk los consejeros de redacción. La revista se propuso a ayudar a que el mundo universitario abandonase sus "ghettos" científicos y académicos para abrirse a sectores más amplios. Sus temas iban desde la crítica cultural (arte, literatura, cine) hasta la política, pasando por la ciencia, la economía, la sociedad y la cultura popular. A cincuenta años de haber editado su primer número, Nexos sigue publicándose. Para una aproximación ver Cabrera López, op. cit., pp. 287-288; Florescano, Enrique, 2008, "Los orígenes", Nexos, enero 2008.

${ }^{9}$ Recuperando el nombre del viejo periódico clandestino del Partido Comunista Mexicano (PCM), aquel que había sido animado en los años veinte por los pintores Diego Rivera y David Alfaro Siqueiros, El Machete. Revista Mensual de Cultura Política salió a la luz en mayo de 1980 y desapareció, tras haber publicado 15 números, en julio de 1981. Dirigida por Roger Bartra, su vida fue breve y explosiva: apenas quince números que se imprimían por veinte mil cada uno. El Machete se caracterizó por la antisolemnidad, el humor gráfico y la introducción de temas ausentes en el mundo comunista: el feminismo y la homosexualidad, el aborto y la legalización de la marihuana, el racismo y el "ecosocialismo". Sobre la intensa vida de El Machete, se puede consultar fueron el bastidor donde la izquierda intelectual mexicana de la época comenzaba a dibujar sus trazos. Pero lejos de ser meros artefactos de difusión partidaria, las revistas se hicieron eco de los ruidos que comenzaron a rugir en aquel verano mexicano. La trayectoria de sus protagonistas, sus temas de debate, sus lenguajes y sus relaciones con la práctica política quedaron grabados en esas páginas donde se dio cita la amplia constelación de la intelectualidad local y latinoamericana. Los subtítulos escogidos por cada una de ellas, la participación de intelectuales exiliados en sus consejos editoriales y la publicación de artículos sobre problemas políticos y culturales propiamente latinoamericanos, no hacían más que ratificar una conjura nuestroamericana. A la Revolución Mexicana le opusieron la Revolución Cubana y a la nación, América Latina.

Cada una de ellas tenía su identidad y su filiación política, delimitadas por sus líneas

Cabrera López, op. cit., pp. 288-294; Concheiro, Luciano, "Historia mínima de... El Machete", en Luciano Concheiro (coord.), El Machete (edición facsimilar), México, FCE/INAH/La Jaula Abierta, 2016, pp. XXVII-XLI; Domínguez Michael, Christopher, "Relectura de El Machete", en Luciano Concheiro (coord.), El Machete (edición facsimilar), México, FCE/INAH/La Jaula Abierta, 2016, pp. LV-LXIV; Illades, Carlos, "El Machete en el debate comunista", Luciano Concheiro (coord.), El Machete (edición facsimilar), México, FCE/INAH/La Jaula Abierta, 2016, pp. XLV-L.

10 La revista Memoria apareció en 1983 como boletín del Centro de Estudios del Movimiento Obrero y Socialista (CEMOS). Fundada por Arnoldo Martínez Verdugo, se trató de una iniciativa del Partido Socialista Unido de México (PSUM). Su Consejo General albergaba figuras como Roger Bartra, Valentín Campa, Rolando Cordera, Arnaldo Córdova, Sergio de la Peña, Pablo Gómez, Gerardo Peláez, Carlos Pereyra, Adolfo Sánchez Rebolledo y Raquel Tibol. En 1987 dejó la "forma boletín" para adquirir el rango de revista. Entre muchos otros, Memoria visitó temas como la historia de las izquierdas en México, la necesidad de las reformas democráticas, la relación entre feminismo y marxismo y la actualidad del comunismo. Con el subtítulo de "Revista de crítica militante" y bajo la dirección de Elvira Concheiro, volvió a publicarse de manera trimestral en 2015, logrando sobrevivir a los diversos avatares del mundo de las izqueirdas mexicana. Ver Pacheco, Víctor Hugo, "1983: nace la revista Memoria", Memoria. Revista de Crítica Militante, número 253, 2015, Pág. 95. 
editoriales, sus directores, sus consejos de redacción, su estética y el público al que se buscaba interpelar. Pero antes que "islas" de pensamiento, funcionaron como redes solidarias de contacto. Cuando una de ellas ponía en circulación un nuevo número, las páginas de las otras eran prestadas como medio de difusión. El mismo gesto se adoptó con los artículos publicados. Como se creía que tenían que estar disponibles para todos los lectores, aparecían replicados aquí y allá. Pero acaso, lo más trascendente haya sido que el campo intelectual funcionó en conjunto. Los intelectuales comprometidos no restringían sus publicaciones a las tribunas de pensamiento que creían más próximas a ellos en términos ideológicos. Por el contrario, participaban en todas ellas. $Y$ todas ellas los exhortaban a participar. Basta observar los nombres de los animadores y colaboradores de cada proyecto para advertir su repetición. Pablo González Casanova y Roger Bartra, Enrique Semo y Carlos Pereyra, Adolfo Gilly y Carlos Monsiváis, nombres fuertes del período, entregaron sus plumas y sus esfuerzos a cada una de ellas.

Curiosamente ausente en trabajos dedicados a investigar las izquierdas mexicanas (como el clásico La izquierda mexicana a través del siglo $X X$, de Barry Carrr ${ }^{11}$, y otro que va en camino de serlo: La inteligencia rebelde, de Carlos Illades $^{12}$. O también Una inquietud de amanecer, de Patricia Cabrera ${ }^{13}$ ), una de las revistas marxistas más destacadas de la época fue Dialéctica. Animada por Gabriel Vargas Lozano, Oscar Walker Cornejo y Juan Mora Rubio, su primer número apareció en julio de 1976. Allí se escribía sobre lucha universitaria tanto como sobre el método dialéctico, el psicoanálisis o el pensamiento de Gramsci y Althusser ${ }^{14}$. La asidua colaboración de intelectuales mexicanos y

\footnotetext{
${ }^{11}$ Carr, op. cit.

12 Illades, op. cit.

${ }^{13}$ Cabrera López, op. cit.

14 Vélez Pliego, Alfonso et. al., "Por una nueva alternativa para el pensamiento crítico", Dialéctica, Año 15, Número 21 (invierno), 1992, pp. 3-6.
}

latinoamericanos exiliados en México, como Sergio Bagú, Roger Bartra, Sergio de la Peña, Oscar del Barco, Bolívar Echeverría, Carlos Franco, Pablo González Casanova, Norbert Lechner, Gérard Pierre-Charles, Carlos Pereyra, Juan Carlos Portantiero, Augusto Salazar Bondy, Adolfo Sánchez Vázquez, Oscar Terán y René Zavaleta Mercado ayudaron a colocar a los términos y conceptos marxistas, a sus debates y discusiones, en un lugar de privilegio. Junto a ellos, textos de Louis Althusser, Christine BuciGlucksmann, Fernando Claudín, György Lukács, Nicos Poulantzas, Biagio de Giovanni y Ludolfo Paramio y Jorge Reverte y entrevistas a Jean Paul Sartre, Étienne Balibar y Georges Labica, Umberto Cerroni, Lucio Colletti y Manuel Sacristán eran convocados para discutir la "crisis del marxismo" y el problema del socialismo y la democracia.

La revista tuvo dos épocas. La primera se extendió a lo largo de 35 números, entre 1976 y 2002. Había tenido una interrupción entre 1988 y 1991, esto es, entre la caída del "Muro de Berlín" y el colapso del "socialismo real". La nueva época, por su parte, se desarrolló entre 2004 y 2015 . Se llegaron a publicar 11 números, de los cuales uno fue doble. ${ }^{15}$ Lamentablemente, Dialéctica dejó de publicarse.

El campo intelectual de las izquierdas latinoamericanas en general, y de las mexicanas en particular, merece emprender una reconstrucción de sus senderos y sus búsquedas, de sus virtudes y sus problemas. En virtud de ello, a continuación, presentamos una entrevista a quien fue su principal animador: Gabriel Vargas Lozano.

Me gustaría comenzar con los orígenes de la revista Dialéctica, teniendo en cuenta las posibles inspiraciones en la elección de su nombre y las decisiones sobre cómo hacer una

\footnotetext{
15 Los números de la primera época se pueden consultar en www.cefilibe.org y en

http://148.206.53.234/revistasuam/Dialectica/. Los de la segunda época se encuentran digitalizados en la página electrónica de la revista http://www.revistadialectica.org/index1.html
} 
revista marxista. De un modo inevitable, el nombre me envía a Dialéctica de Aníbal Ponce ${ }^{16}$ y a la parisina Dialectiques ${ }^{17}$. $Y$ en términos temáticos, y hasta de disposición espiritual frente al marxismo, en el sentido de ponerlo a dialogar y discutir con las expresiones más avanzadas de la "ciencia burguesa" como el psicoanálisis, el cristianismo o la filosofía de Heidegger, me recuerda mucho a la revista argentina Pasado y Presente ${ }^{18}$, indisolublemente

16 Bajo la dirección del marxista argentino Aníbal Ponce, Dialéctica fue editada en Buenos Aires durante 1936. A lo largo de sus siete números publicó textos de Marx, Engels, Lenin, Plejanov, Anatoli Lunacharsky, Geörgy Lukács, Paul Lafargue y Ferdinand Lasalle, entre muchos otros.

17 Dialectiques. Revue trimestrielle fue una revista marxista dirigida por David Kaiserbruger. Apareció en París en 1973 y declinó en 1981, luego de haber publicado 33 números. Sus temas de interés giraron en torno del eurocomunismo, el socialismo y la democracia, la teoría del Estado y la "crisis del marxismo", el problema de la historia y la filosofía, la obra de Gramsci y Althusser. Algunos de los intelectuales que publicaron en sus páginas fueron Jean-Claude Chevalier, Marc Abeles, Christine Buci-Glucksmann, Hugues Portelli, Luciano Gruppi, Nicola Badaloni, Valentino Gerratana, Georges Labica, Nicos Poulantzas y Antonio Negri.

18 Fundada por un grupo de intelectuales expulsados del Partido Comunista Argentino (José María Aricó, Oscar del Barco, Samuel Kieczkovsky, Juan Carlos Portantiero, Héctor Schmucler), la revista Pasado y Presente se publicó en dos épocas. Editada en la Ciudad de Córdoba entre 1963 y 1965, los 9 números de la primera época salieron bajo la dirección de Oscar del Barco y Aníbal Arcondo. Ya con sede en Buenos Aires y con la dirección de Aricó, la segunda época publicó sólo 3 números, todos durante 1973. Con los aportes y reflexiones de Gramsci como faro teórico-político, y con una mirada que privilegiaba las novedades ofrecidas por la izquierda italiana, la revista proyectó una interesante renovación de las lecturas del marxismo en Argentina en el marco de la llamada "nueva izquierda". En Pasado y Presente aparecieron artículos dedicados a reflexionar sobre el castrismo y el guevarismo, las vanguardias y los sujetos políticos revolucionarios, el peronismo y el sindicalismo clasista y combativo, la teoría de la dependencia y el psicoanálisis, el Tercer Mundo y la descolonización. Para una profundización, recomendamos Burgos, Raúl, "Entre Gramsci y Guevara: la primera etapa de la revista Pasado y Presente" y "La segunda etapa de la revista Pasado y Presente, Montoneros y la lucha armada", Los gramscianos argentinos. Cultura y política en la experiencia de Pasado y Presente, Buenos Aires, Siglo XXI, 2004, pp. 68-106 y 206-224; González, Horacio, "Pasado y Presente: la tragedia de los gramscianos argentinos", Revista Pasado y Presente. Tomo I. ligada al nombre de José Aricó, y en la que había participado Oscar del Barco, una figura que intuyo importante en la experiencia de Dialéctica -y sobre quien me gustaría volver más adelante

La revista Dialéctica se originó en una circunstancia especial por la que atravesaba la Universidad Autónoma de Puebla (UAP). En esa Universidad, en la década de los sesenta del siglo pasado, surgió un movimiento de jóvenes que se opusieron tanto al autoritarismo del gobierno como a un medio extremadamente conservador. Ese movimiento fue reprimido en 1968, como ocurrió en la Ciudad de México en donde, como se sabe, el gobierno federal llevó a cabo la matanza del 2 de octubre en la Plaza de las Tres Culturas en Tlatelolco. En el Estado de Puebla también se llevó a cabo una gran represión en contra del movimiento estudiantil. En julio de 1972 asesinaron al líder estudiantil Joel Arriaga Navarro y en diciembre, a Enrique Cabrera Barroso y al año siguiente a otros estudiantes más. La Universidad entonces se convirtió en el bastión de la izquierda, hegemonizada, en aquel momento, por el Partido Comunista Mexicano (PCM). Ahora bien, en esta situación, ya en la década de los sesenta, y para ser precisos, en 1976, un grupo de profesores de la Escuela de Filosofía y Letras, consideramos que era necesario dar origen a un órgano teórico de buen nivel y en el que la Universidad demostrara que no sólo defendía las causas populares, sino que también podía propiciar publicaciones académicas serias desde una posición crítica. Esa iniciativa la encabezamos y llevamos a la práctica un filósofo colombiano llamado Juan Mora Rubio, quien era profesor de la Facultad de Filosofía y Letras y yo, que en ese momento era profesor de medio tiempo en la Facultad de Filosofía y Letras de la Universidad Nacional Autónoma de México

Primera época (1963-1965): edición facsimilar, Biblioteca Nacional, Buenos Aires, 2014, pp. 7-23; Cortés, Martín, "La revista Pasado y Presente", Un nuevo marxismo para América Latina. José Aricó: traductor, editor, intelectual, Buenos Aires, Siglo XXI-CCC, 2015, pp. 52-64. 
(UNAM) y profesor visitante en la UAP, a la que acudía cada fin de semana a impartir cursos. En la fundación de la revista nos acompañaron varios profesores como Roberto Hernández Oramas, Angelo Altieri Megale, Oscar Correas, Rafael Peña, Alfonso Vélez Pliego, quien después sería Rector de la Universidad, entre otros.

El nombre de Dialéctica fue propuesto por Altieri quien era un filósofo y lingüista italiano que residía en Puebla y quien había sido director de la Escuela de Filosofía y Letras, que después se convirtiera en Facultad. A todos nos pareció bien el nombre ya que consideramos que era, por un lado, la concepción básica de Marx y Engels y por otro, la herencia de una tradición muy importante que se había inaugurado con Heráclito. No tuvimos presente, en ese momento, a la revista Dialéctica de Ponce (quien, como tú sabes, infortunadamente murió muy joven en el exilio mexicano y sobre el que escribí un amplio ensayo que publiqué en mi libro Intervenciones filosóficas: ¿Qué hacer con la filosofía en América Latina?"19) y tampoco al grupo "Pasado y Presente", que se haría presente más tarde en Puebla y con el que tuvimos encuentros y desencuentros, especialmente con Oscar del Barco, aunque eso fue después de un año de haber fundado la revista. Con Dialectiques tuvimos intercambio y de Francia fueron un gran apoyo Georges Labica y Jacques Bidet. Por cierto, el último nos incluyó en el Dictionnaire Marx Contemporain ${ }^{20}$.

En términos del debate intelectual, Dialéctica nace en un contexto muy preciso que se hizo conocido como la "crisis del marxismo". Teniendo en cuenta esto, ¿cuáles fueron las razones teórico-políticas que los impulsaron a publicar una revista marxista? ¿Qué debates querían dar en la cultura de izquierdas mexicana

\footnotetext{
19 Vargas Lozano, Gabriel, Intervenciones filosóficas: ¿Qué hacer con la filosofía en América Latina?, Toluca, UAEM, 2007.

${ }^{20}$ La entrada se puede ver en Bidet, Jacques, "Panorama de revistas", Dictionnaire Marx Contemporain, París, PUF, 2001, pp. 553-554.
}

tanto como en la internacional? ¿Qué vacío se buscaba llenar? Me refiero a sí había algo, ya sea en la orientación político-intelectual de la revista, en los contenidos temáticos o en la disciplina académica, que creían ausente en otras revistas contemporáneas y marxistas como Historia y Sociedad o Cuadernos Políticos.

Por un lado, como he dicho anteriormente, queríamos defender a la UAP de los ataques que decían que sólo le interesaba la agitación política. Por cierto, quiero aquí agregar que en las décadas de los sesenta y setenta, las Universidades eran los únicos lugares en que se había logrado cierta libertad de expresión y organización política, ya que ésta no existía en lo que llamaríamos "sociedad civil". Estas libertades se lograron hasta 1977, cuando el gobierno y los partidos de oposición firmaron un pacto que tuvo por objetivo reconducir la lucha política por la vía democrática. Sin embargo, la revista Dialéctica tenía también el propósito de coadyuvar al esclarecimiento de la problemática que enfrentaba la izquierda en México, Latinoamérica y el mundo especialmente desde la filosofía marxista, aunque también publicamos ensayos de ciencias sociales y eventualmente crítica literaria. A nuestro juicio, algunas revistas cumplían un papel importante desde el punto de vista de las ciencias sociales, pero faltaba el debate filosófico desde el punto de vista de un marxismo crítico. Para ello pudimos lograr colaboraciones de muy diversas personalidades como Pablo González Casanova, Adolfo Sánchez Vázquez, Luis Villoro, Sergio Bagú, René Zavaleta Mercado, Georges Labica, István Mészáros, Adam Schaff, Umberto Cerroni, Manuel Sacristán, Perry Anderson, Wenceslao Roces, Luis Cardoza y Aragón, Gerard Pierre-Charles y muchos otros pensadores de primer orden que nos dieron extraordinarias colaboraciones. Se trataba de llenar un vacío en la izquierda mexicana en el mismo sentido en que habían buscado hacerlo Historia y Sociedad y Cuadernos Políticos, aunque nosotros acentuando el lado filosófico. En este sentido, aprovechamos que en la UAP se organizaron 
durante las décadas de los setenta y ochenta una serie de coloquios internacionales a los que vinieron algunos de los más importantes pensadores marxistas de Europa. Pero, además, Dialéctica organizó sus propios eventos. Uno de los más relevantes fue la iniciativa de conmemorar el aniversario de la muerte de Marx, el 14 de marzo de 1983. La idea fue del comité de redacción de la revista y fue apoyada por la UAP. A principios de ese año, citamos a una reunión en el auditorio de la cafetería Gandhi y nuestra sorpresa fue que acudieron los personajes más representativos de la izquierda mexicana, como Arnoldo Martínez Verdugo, Valentín Campa, Heberto Castillo, Pablo González Casanova, Sánchez Vázquez y muchos más. Allí se eligió un comité coordinador que encabecé y se programaron una serie de actividades para ser realizadas todo el año. El acto culminante fue la reunión en el Palacio de Bellas Artes. No era extraño que fuera allí, porque en ese lugar se había celebrado en los años cuarenta la "Mesa redonda de los marxistas mexicanos" y se habían realizado ceremonias luctuosas de los grandes pintores comunistas como Diego Rivera o Frida Kahlo. Lo que ocasionó una gran controversia pública fue la definición de los oradores. Adolfo Gilly propuso a Rosario Ibarra de Piedra, quien se había convertido en un símbolo de la denuncia de los desaparecidos políticos (entre ellos, su propio hijo). El comité aceptó integrarla en el presídium, pero no como oradora, y ese hecho puso furiosos a muchos, empezando por el propio Gilly. Luego, también se excluyó a González Casanova sin que se hicieran explícitas las razones. Posiblemente, esas controversias hicieron que el día 14 acudieran a Bellas Artes miles de personas y escucharan las hermosas palabras de Luis Cardoza y Aragón, así como las excelentes intervenciones de Wenceslao Roces, Sánchez Vázquez, Jaime Labastida y Roger Bartra, quien creo que en ese momento todavía se consideraba marxista. A mi juicio, debieron de haber intervenido también Valentín Campa, gran líder ferrocarrilero que había pasado once años en la cárcel como preso político, y Raquel Tibol, gran historiadora y crítica de arte mexicano. Lo que, a mi juicio, desentonó bastante fue la decisión de Bartra de invitar a su amiga Betsi Pecanins y su grupo a interpretar piezas de jazz. A mí el jazz de gusta y Betsi lo interpretaba maravillosamente, pero no se trataba de organizar un acto surrealista digno de André Breton. ${ }^{21}$

Posteriormente, Dialéctica organizó otros coloquios que tenían el objetivo de esclarecer diversas problemáticas de la izquierda, como fue el caso del titulado "Marxismo y cultura política en la crisis actual" (al que le dedicamos un número especial)" en 1987 o la "Primera conferencia de filósofos y científicos sociales de México-Estados Unidos-Canadá". En este coloquio los Radical Philosophers de Estados Unidos y Canadá dialogaron con sus pares mexicanos con extraordinarios resultados. EI coloquio lo abrió Sánchez Vázquez y lo clausuró González Casanova, con conferencias memorables. Aquí me gustaría agregar que, desde mi punto de vista, hacía falta, en los partidos de izquierda, mayor debate teórico para esclarecer problemas como la llamada "crisis del marxismo", la naturaleza de los países socialistas, la relación entre el marxismo y la teología de la liberación y los múltiples problemas teóricopolíticos. Curiosamente, frente a estas posiciones se encontraba la concepción liberal-conservadora de Octavio Paz y su grupo, primero a través de la revista Plura ${ }^{23}$ y luego de la revista Vuelta ${ }^{24}$.

\footnotetext{
21 El coloquio, titulado "Conmemoratorio del centenario de la muerte de Carlos Marx", puede revisarse en Dialéctica, Año VIII, número 14-15, diciembre marzo, 1983.

22 Entre otros, participaron del coloquio Pablo González Casanova, Sergio Bagú y Horacio Cerruti Guldberg. Se puede consultar en Dialéctica, Año XIII, número 19, julio 1988.

23 Plural salió publicada de manera mensual entre 1971 y 1976, como suplemento del diario Excélsior en la época de Julio Scherer García. Bajo la dirección de Octavio Paz, se editaron 58 números. Su consejo editorial estuvo conformado por Tomas Segovia, José de la Colina, Salvador Elizondo, Juan García Ponce, Alejandro Rossi, Gabriel Zaid y Kazuya Sakai. De clara orientación literaria, la revista tuvo un perfil cosmopolita, pero crítico de la Modernidad. Preocupada por el problema de la democracia fue crítica de la Unión Soviética y los países del mundo socialista. Allí se publicaron artículos de Lévi-Strauss, Elena Poniatowska,
} 
Sobre la "crisis del marxismo" publicamos en varias entregas un librito excelente de Umberto Cerroni, quien también nos apoyó ${ }^{25}$. El traductor fue Roberto Hernández Oramas, quien en la segunda época figuró como co-director de la revista. De igual forma, publicamos un esclarecedor texto de Perry Anderson que fue producto de una conferencia que dictó en Puebla a invitación nuestra. ${ }^{26}$

Tratándose de una revista universitaria, ¿cuáles eran los problemas a los que se enfrentaba Dialéctica? ¿Tenían alguna estrategia -narrativa o de otra índole- para salir de los muros académicos?

Dialéctica era una revista que se producía en la Universidad, pero estaba dirigida especialmente al mundo cultural y político. Desgraciadamente arrastramos siempre el problema de la distribución, ya que las

Carlos Fuentes, y Gustavo Sainz, entre otros. Tras el golpe que destituyó a Scherer de la dirección de Excélsior, Paz y su equipo renunciaron a Plural y fundaron Vuelta. Ver LópezKijares, Antonio, La vida política de México y la revista Plural de Octavio Paz (1971-1976), México, ITAM.

${ }^{24}$ Fundada y dirigida por Octavio Paz tras el golpe contra Julio Scherer en 1976, Vuelta editó 83 números entre 1976 y 1998, año de la muerte de Paz. También fueron parte de la fundación de Vuelta Alejandro Rossi, José de la Colina, Juan García Ponce, Salvador Elizondo, Enrique Krauze, Tomás Segovia, y Gabriel Zaid. Como Plural, Vuelta también fue crítica del mundo comunista (Unión Soviética, Cuba, Nicaragua). Entre sus páginas se pueden encontrar colaboraciones de Guillermo Cabrera Infante, Mario Vargas Llosa, Guillermo Sucre, Jorge Edwards, Ida Vitale, Jorge Semprún, Raymond Aron y François Furet. Para una profundización ver Perales Contreras, Jaime, Vuelta, origen y desarrollo de una revista intelectual (1976-1986), México, ITAM, 1990; Castañón, Adolfo, "Una historia personal de Vuelta", Saúl Susnowski (ed.), La cultura de un siglo. América Latina en sus revistas, Buenos Aires, Alianza, 1999, pp. 515524; y Domínguez Michael, Christopher, "Las batallas políticas", Letras Libres, Número 96, diciembre 2006.

25 Se trata de una larga entrevista realizada en 1978 por Roberto Romani. Con el título de "¿Crisis del marxismo? Entrevista filosófico-política a Umberto Cerroni", Dialéctica la publicó en cuatro entregas sucesivas, entre los números 11 y $14-15$

26 Anderson, Perry, “¿Existe una crisis del marxismo?”, Dialéctica, Año V, número 9, diciembre 1980, pp. 145-158.
Universidades son una nulidad al respecto. Tuvimos nosotros que estar presentándola en diversos lugares del país y la llevábamos a todos los congresos en los que participábamos. Entre otros, recuerdo haber llevado la revista a un congreso internacional celebrado en Rostock, en la entonces República Democrática de Alemania, justamente en 1989, un poco antes de la Caída del muro de Berlín y también a otro en Bulgaria sobre "Lenin y la cultura". Esa tarea también la hicieron otros compañeros. En otras palabras: la difusión fue siempre nuestro gran problema, sin embargo, logró un buen público interesado en el pensamiento crítico. Hoy, curiosamente, nos enfrentamos a un gran vacío en ese aspecto.

Hace un rato me decías que cuando nació Dialéctica la UAP era el bastión de una izquierda hegemonizada por el PCM. Me interesaría ahondar sobre esa "huella originaria", sobre teniendo en cuenta que tanto durante su nacimiento como en toda la primera época de la revista (al menos hasta su primera interrupción, en 1988), los rectores de la Universidad eran militantes comunistas (Luís Rivera Terrazas, al que en otro lugar definiste como un "entusiasta animador de la revista"27, entre 1975 y 1981, y Alfonso Vélez Pliego, entre 1981 y 1987). ¿Cómo era la relación de Dialéctica con el Partido? Estoy pensando en aquel editorial que escribiste sobre el rol del PCM durante el proceso de elección de rector en 1981

En primer lugar, quiero decir que la revista gozaba de autonomía absoluta tanto de las autoridades de la Universidad como del PCM. Jamás recibimos la más ligera indicación. Por otro lado, la mayoría de los miembros del consejo de redacción no éramos miembros de dicho Partido. El Rector Rivera Terrazas nos apoyó siempre sin pedir nada a cambio. Lo que ocurrió fue que al

27 Ver Vargas Lozano, Gabriel y Hernández Oramas, Roberto, "Veinticinco años de Dialéctica", Utopía y praxis latinoamericana, Año 6, Núm. 14, septiembre 2001, pp. 132134. 
terminar su período tanto él como el Partido lanzaron su propio candidato -Luís Ortega Morales-, lo que implicó una contradicción interna con el grupo dirigido por Vélez Pliego. Fue una escisión en el seno del PCM que implicaba también dos concepciones de la Universidad: en un caso, el sostenimiento de una Universidad muy vinculada a las luchas populares, y en el otro, atender las labores sustantivas de la Universidad sin dejar el compromiso social. Como tú mencionas, yo publiqué en Dialéctica ese ensayo llamado "Crónica de una elección anunciada" ${ }^{28}$. Ahora bien, la división no fue sólo en Puebla sino también a nivel nacional. Recuerdo los sendos desplegados nacionales en los que Sánchez Vázquez encabezaba el apoyo a Vélez Pliego y Enrique Semo, gran historiador y amigo de Dialéctica, los del otro candidato, Ortega Morales. El enfrentamiento entre las dos fuerzas fue muy grande y dividió a estudiantes, profesores y trabajadores.

Finalmente ganó Vélez Pliego, pero antes de que el PCM se disolviera para dar lugar al Partido Socialista Unificado de México (PSUM), expulsó a Vélez por haber desobedecido la decisión del Partido.

¿Cómo continuó la relación entre la Dialéctica y el PCM/ PSUM luego de las elecciones y la expulsión de Vélez Pliego? ¿Y la relación entre el Partido y la Universidad?

Como dije anteriormente, la ausencia de libertades políticas en México implicó que la acción de los partidos de izquierda lograra refugio en la Universidad, pero al firmar el pacto político los partidos ya podían actuar en otros sectores con mayor libertad. Así que el cambio de Rector en la UAP, que después se denominó BUAP (Benemérita), se da en esa coyuntura. En otras palabras, la Reforma Política de 1977 colocó a la izquierda, y en especial al PCM, en la necesidad de transformarse para hacerse menos rígido en el

28 Vargas Lozano, Gabriel, “Crónica de una elección anunciada", Dialéctica, Año VI, número 11, diciembre 1981, pp. 5-18. plano doctrinario y político. Así, el PCM decidió terminar con su existencia y dar lugar al PSUM.

A mi juicio, el PSUM amplió su concepción teórico-política en un sentido en que coincidía con muchas de las tesis sostenidas por la revista. Así que no hubo contradicción o enfrentamiento. En el caso de la Rectoría de Vélez, la Universidad se mantuvo en una posición de relativa autonomía frente al Estado y recompuso sus relaciones con el PSUM.

¿Qué relación tenía la revista con otros proyectos editoriales de la UAP, como por ejemplo la Colección Filosófica del Instituto de Ciencias? ${ }^{29}$ Estoy pensando en el hecho de que el director de la Editorial, Oscar Walker Cornejo, y el director de la Colección, Oscar del Barco, eran parte del Comité de Dirección de Dialéctica, y en que vos también participaste de la Colección a través de la preparación del número $13^{30}$. Pero

\footnotetext{
29 Siempre bajo la dirección de del Barco, la Colección Folosófica funcionó entre 1977 y 1985, publicando 20 números. El primero fue El marxismo y Hegel, de Lucio Colletti y Valentino Gerratana, y el último Discutir Mariátegui, de Oscar Terán. Entre los títulos de esta interesantísima Colección destacan El marxismo y la crisis de Estado (con textos de Nicos Poulantzas y Christine BuciGlucksmann, entre otros y otras), Esencia y apariencia en $\mathrm{El}$ Capital, de Oscar del Barco, ¿Existe una teoría marxista del Estado (Norberto Bobbio, Umberto Cerroni, Giuseppe Vacca, Valentino Gerratana, Archille Occhetto y Pietro Ingrao), El problema del Estado y la dictadura del proletariado (Nicos Poulantzas, Etienne Balibar, Luciano Gruppi y Georges Labica, et al), El pensamiento revolucionario de Gramsci (Eric Hobsbawm, Lucio Magri, Rossana Rossanda, Cerroni y Colletti, et al), Acerca de la naturaleza social de la Unión Soviética (Paul Sweezy, André Gunder Frank, Ernest Mandel, Ralph Milliband, Ludolfo Paramio, et al), La crisis del marxismo (Louis Althusser, Colletti, Buci-Glucksmann, Fernando Claudín, Ludolfo Paramio y Jorge Reverte) y Movimientos populares y alternativas de poder en Latinoamérica (Enzo Faletto, Carlos Franco, Sergio de la Peña, Adolfo Gilly, Norbert Lechner, Oscar del Barco y Héctor Bruno, et al).

30 Ideología, teoría y política en el pensamiento de Marx, Puebla, ICUAP 1980. Además de escribir la "Introducción" y una cronología de la vida y la obra de Marx, Vargas Lozano colaboró con uno de los capítulos. El resto de los artículos fueron escritos por Angelo Altieri, Umberto Cerroni, Helmut Reichelt, Oscar del Barco, Román Rosdolsky, Jorge Juanes y Juan Mora Rubio.
} 
también estoy pensando en la afinidad temática, metodológica y hasta ideológica de ambos proyectos, en su crítica del "marxismoleninismo" y en su interés por desacralizar al marxismo desde el marxismo, por desdogmatizarlo y ponerlo en diálogo con otras corrientes...

Nuestra posición, desde el punto de vista del marxismo siempre fue crítica y abierta. Nos opusimos a la versión del llamado "Diamat" de factura soviética y de origen estalinista. Consideramos que había que abrir nuevos espacios y en nuestra revista publicamos textos diversos de Foucault, Nietzsche e inclusive una entrevista crítica del marxismo de Apel. Yo publiqué en una colección de la Universidad mi antología titulada Ideología, teoría y política en Marx. Podríamos decir entonces que había un paralelismo temático entre lo que se publicaba en la UAP, pero no necesariamente una coincidencia teórica ya que la colección la dirigía Oscar del Barco de acuerdo a sus propias concepciones.

Me gustaría que me cuentes un poco cómo fue la incorporación de del Barco a la revista y cómo se desarrolló la relación con él y con sus posturas teórico-políticas respecto del marxismo en general y de Lenin en particular (expresada muy particularmente en ese polémico libro que fue Esbozo de una crítica a la teoría y práctica leninistas ${ }^{31}$, publicado justamente por la Colección filosófica de la editorial de la UAP)

Cuando del Barco llegó a la Universidad a finales de los años setenta, inmediatamente lo invitamos a formar parte de la revista. Ahora bien, yo creo que del Barco se fue más allá del marxismo y pasado el tiempo tuvimos dos desencuentros. Uno fue a propósito de Octavio Paz: mientras del Barco lo admiraba y lo consideraba "otro Borges", nosotros creíamos

\footnotetext{
31 Del Barco, Oscar, Esbozo de una crítica a la teoría y práctica leninistas, Puebla, ICUAP, 1980.
}

que su posición política era la de golpear a la izquierda con el apoyo de todos los medios de comunicación burgueses, pero sin tocar al capitalismo. Nosotros, es decir, la mayoría del consejo, consideramos que, más allá de sus aportes literarios, Paz y su grupo estaban cumpliendo una función coincidente con toda la ofensiva desarrollada por los Estados Unidos en contra del socialismo. Por ejemplo, atacaban a Cuba por la ausencia de libertades, en especial para los intelectuales, pero no condenaban el bloqueo norteamericano a la isla; atacaban al marxismo soviético, pero nunca dijeron que había varias corrientes muchas de las cuáles eran críticas de las burocracias que gobernaban aquellos países. En otras palabras, su crítica era parcial. En este sentido, recuerdo que Paz organizó un coloquio internacional para celebrar los funerales del llamado "socialismo real" con el apoyo de Televisa y un gran despliegue publicitario $^{32}$. Para ello, se trajo a muchos disidentes que, obviamente, hicieron una crítica muy fuerte a aquellas sociedades que se habían derrumbado, pero que no hicieron una diferenciación entre el pensamiento de Marx y la deformación de su pensamiento bajo el estalinismo, y mucho menos de un marxismo crítico y uno dogmático. Eso lo hizo, para gran molestia de todos los invitados, Sánchez Vázquez, quien, casi a la fuerza, tuvo el tiempo para exponer otra forma de entender la caída de los regímenes Ilamados socialistas. Sánchez Vázquez, por cierto, había considerado que aquellos regímenes no eran socialistas sino una "transición bloqueada" al socialismo. Otro ejemplo de la unilateralidad de Paz en aquel coloquio fue que,

\footnotetext{
32 Organizado por Octavio Paz y la revista Vuelta, "El encuentro Vuelta: la experiencia de la libertad" se llevó a cabo en la Ciudad de México, entre el 27 de agosto y el 1 de septiembre de 1990. Entre los más de cuarenta intelectuales de todo el mundo que participaron, destacaron Mario Vargas Llosa -allí acuñó la célebre caracterización del Partido Revolucionario Institucional (PRI) como una "dictadura perfecta"-, Norman Manea, Agnes Heller, Jean François Revel, Cornelius Castoriadis, Adolfo Sánchez Vázquez, Arnaldo Córdova, Luís Villoro, Carlos Monsiváis, Héctor Aguilar Camín y Enrique Krauze, entre otros y otras.
} 
según él, había una conexión intrínseca entre economía de mercado y democracia, frente a lo cual el escritor chileno Jorge Edwards le contestó, con la voz adelgazada de un tímido alumno frente al maestro, que en Chile había economía de mercado, pero no democracia, que, por cierto, había sido suprimida sangrientamente por Pinochet, entre otras cosas.

La segunda controversia con del Barco fue sobre la Revolución Cubana y, especialmente, sobre la figura de Fidel Castro. Varios de nosotros consideramos que se podía hacer la crítica al "socialismo real" que se quisiera, a la que estimábamos necesaria, pero que no podíamos caer en una identificación con toda la crítica alentada por los medios de comunicación controlados por el imperio o hacer tabula rasa sobre el bloqueo a la isla. Y que, por otro lado, Fidel Castro era un gran líder mundial antiimperialista. Esas dos polémicas llevaron a Del Barco a presentar su renuncia al consejo editorial de Dialéctica.

A finales de los años setenta y a principios de los ochenta, un grupo de intelectuales argentinos exiliados en México editaron la revista Controversia. Para el examen de la realidad argentina ${ }^{33}$ (de la que del Barco

\footnotetext{
33 La revista Controversia. Para el examen de la realidad argentina fue editada en México entre octubre de 1979 y agosto de 1981. Jorge Tula era el director y el consejo editor, que mezclaba socialistas y peronistas de izquierda, estuvo conformado por Carlos Ábalo, José Aricó, Sergio Bufano, Nicolás Casullo, Rubén Sergio Caletti, Ricardo Nudelman, Juan Carlos Portantiero, Héctor Schmucler y Oscar Terán. A lo largo de sus 13 números se discutieron temas como la "crisis del marxismo", las relaciones entre socialismo y democracia, las vanguardias políticas, el foquismo, los derechos humanos, el peronismo, el exilio y la derrota política de los movimientos populares en la década del setenta. Para una profundización se puede consultar Gago, Verónica, Controversia: una lengua del exilio, Buenos Aires, Biblioteca Nacional, 2012; Giller, Diego, "La revista de la derrota. Exilio y democracia en Controversia (1979-1981)", Latinoamérica. Revista de estudios latinoamericanos, año 13, n. 63, junio-diciembre 2016, pp. 37-64; y Giller, Diego, “Crítica de la razón marxista. 'Crisis del marxismo' en Controversia (1979-1981)", Revista Mexicana de Sociología, núm. 79, julio-septiembre 2017, pp. 487-513.
}

fue un asiduo colaborador, llegando a tener un acalorado debate sobre la "crisis del marxismo" con los españoles Ludolfo Paramio y Jorge Reverte). Pensando en los nexos posibles entre las izquierdas argentinas en el exilio $y$ las izquierdas mexicanas, y teniendo en cuenta las "afinidades electivas" entre Controversia y Dialéctica (la interrogación por el vínculo entre socialismo y democracia, la preocupación por la "crisis del marxismo", etc.), me gustaría saber si existió algún tipo de vínculo entre ambas revistas, algún ámbito de debate común, etc...

No tuvimos relaciones con la revista Controversia como tal, aunque, como dices, sí con algunos de sus miembros. En efecto, a fines de los setenta llegaron miembros del grupo "Pasado y Presente" a Puebla. La labor del grupo argentino fue realmente significativa y sus libros muy apreciados. Aricó residió en la Ciudad de México y trabajó en la Editorial Siglo XXI. Fue un muy destacado intelectual a quien leímos siempre con mucho interés, desde su Marx y América Latina $^{34}$ hasta sus trabajos sobre Gramsci, Mariátegui, etc. Con Terán la relación fue muy cordial y publicamos sus trabajos sobre Foucault y Mariátegui como una buena aportación al conocimiento de dichos autores.

Nuestro país, en general, se ha beneficiado con los exilios desde el punto de vista teórico. Han venido los mejores intelectuales de Guatemala, Chile, Argentina, Haití, Brasil, Uruguay y ya no se diga el exilio español del ' 39. Eso ha implicado un enorme impulso que mucho agradecemos. En algún trabajo he señalado la importancia de haber impulsado en México, la nueva lectura de Gramsci en los ochenta, sobre todo con Juan Carlos Portantiero, quien colaboró en nuestra revista.

Interrogado por las razones por las cuales Cuadernos Políticos había dejado de aparecer, uno de sus animadores, Bolívar Echeverría, respondió que el colapso de la URSS

34 Aricó, José, Marx y América Latina, Buenos Aires, Catálogos, 1982. 
significó el fin de un tipo de publicaciones que eran críticas y de izquierdas ${ }^{35}$. ¿Cómo posicionarías a Dialéctica frente a esta afirmación, sobre todo teniendo en cuenta que la primera época de la revista se reinició justamente en 1991 con un número dedicado al "colapso del socialismo real"? ¿Cómo definirías ese reinicio en relación con la falta de la URSS en tanto que "referente real"?

El derrumbe del socialismo real en Europa del Este y la URSS fue un golpe tremendo para la izquierda. Frente a este golpe se presentaron varias posturas: una de ellas fue la del triste espectáculo de los oportunistas, que primero eran comunistas ortodoxos y luego reaparecieron social-liberales o inclusive neoliberales; otra fue el caso de algunos de los miembros de Cuadernos Políticos, quienes consideraron que su labor crítica había terminado, al menos, a través de la revista. Desde mi punto de vista, esa posición fue errónea. Gente tan destacada como la que formó esa revista no debería haber dejado de publicar, sino todo lo contrario. A mi juicio, se requería explicar, desde el punto de vista marxista, cuáles habían sido las causas del derrumbe y cuáles las consecuencias, pero con la necesidad de mantener nuestras posiciones, que nunca habían sido a favor de las burocracias que mal gobernaron esos países. Como recordarás, publiqué en Siglo XXI un libro denominado Más allá del derrumbe: Socialismo y democracia en la crisis de civilización europea ${ }^{36}$, en donde busqué explicar (y explicarme) por qué había ocurrido el derrumbe del Ilamado "socialismo real" y cuáles eran las consecuencias. Lo lamentable era que en el ambiente intelectual de la izquierda mexicana había cundido la decepción y la desesperanza y,

\footnotetext{
35 Echeverría, Bolívar, 1995, "La ERA de Cuadernos Políticos", en Fernando Benítez (Ed.), AA. VV., Ediciones era 35 años. Neus Espresate. Guadalajara, Universidad de Guadalajara, 1995, pp. 35-40.

${ }^{36}$ Vargas Lozano, Gabriel, Más allá del derrumbe: Socialismo y democracia en la crisis de civilización europea, Ciudad de México, Siglo XXI, 1994.
}

por tanto, mi libro cayó en una especie de vacío. Agregaré algo significativo: el libro pretendía que se continuara el debate en la izquierda, pero en forma sintomática y sin advertirme previamente, la revista Memoria (de la cual formaba parte del consejo editorial -y aún hoy lo sigo siendo) me sorprendió con la publicación de un virulento ataque en mi contra por parte de un historiador polaco residente en México, y que había tenido una relación de amistad conmigo, llamado Jan Patula. En ese momento, la revista era dirigida por un escritor llamado José Ángel Leyva a quien, seguramente, le pareció divertido iniciar una polémica para atraer lectores. El ataque principal de Patula era que yo era un estalinista embozado y que, en el fondo, quería defender al "socialismo real". Mi sorpresa radicaba en varios puntos: 1) en primer lugar, el director debería haberme dado a conocer el texto como miembro del Consejo, no para censurarlo sino para responderle en el mismo número. No lo hizo; 2) pero lo más extraño fue que los miembros del consejo editorial, en lugar de promover una amplia polémica sobre los importantísimos temas del derrumbe de los regímenes socialistas, le dieron a la polémica el carácter de un "pleito" entre dos personas que era, por cierto, lo menos importante; 3 ) además, yo, por mi edad, jamás fui estalinista sino más bien, en un principio, partidario de Sartre, Marcuse, Russell, Frantz Fanon, el Che Guevara, etc., es decir, de algunos de los pensadores más influyentes en mi generación, que es la del movimiento estudiantil de 1968. Lo que pasaba era que a Patula lo habían maltratado mucho las burocracias polacas y ahora tomaba venganza, pero con la persona equivocada. Aún más, en Dialéctica publicamos una primicia mundial en español que él nos proporcionó y que nos pareció muy interesante: el programa de Solidaridad del movimiento polaco. Todo ello me develó un problema: en ese momento, los compañeros de Memoria, entre los que figuraban destacados intelectuales, no querían tratar el asunto seriamente. A pesar de todo, en Memoria se publicaron otros artículos que se opusieron a la versión de Patula. 
En el caso de Dialéctica, después de un período de suspensión de su publicación, la revista inició una segunda época, en la cual cambiamos el formato para volverlo más atractivo. $Y$ además, en el primer número publicamos textos muy valiosos justamente sobre el derrumbe y sobre Cuba.

Sobre el "referente", el llamado "socialismo real", cuyo paradigma fue la concepción estalinista o neo-estalinista, nunca fue nuestro referente. Nuestro referente es el capitalismo real y su impugnación crítica.

En un artículo reciente, Massimo Modonesi señaló que "en México existe actualmente sólo una revista con un inequívoco perfil de izquierda publicada en papel y con una distribución bastante limitada; la "revista de crítica militante" Memoria" ${ }^{37}$. ¿Estás de acuerdo con esa caracterización del mundo intelectual de las izquierdas mexicanas? ¿Dónde ubicarías hoy a Dialéctica frente a esta opinión?

Lamentablemente Massimo se olvidó de Dialéctica como lo han hecho otros estudiosos. En el caso de Memoria, yo he participado desde hace muchos años en el consejo editorial y he colaborado en ella con cierta frecuencia. Lo que ocurre, a mi juicio es que la izquierda no ha podido sostener un medio de difusión atractivo, interesante, con buenos debates; que se publique en papel, pero también en internet y que sepa atraer a un amplio grupo de colaboradores de todas las generaciones. Hace falta una alternativa a las dos revistas que hoy aparecen en nuestro país sostenidas por un buen número de anuncios de las secretarías del gobierno, como Nexos y Letras libres. Sin menospreciar la importante labor de Memoria, hace falta una mayor influencia en el medio cultural, pero aquí hay que atender un problema que ha afectado a los

37 Modonesi, Massimo, "Lecturas de las izquierdas mexicanas", Nueva Sociedad, n² 268, marzo-abril, 2017, pp. 100-109, disponible en http://nuso.org/media/articles/downloads/6.TC Modonesi 268.pdf artistas, escritores e investigadores universitarios: el gobierno de Salinas de Gortari, creó, maquiavélicamente, el Sistema Nacional de Creadores (SNC) y el Sistema Nacional de Investigadores (SIN) y al otorgar buenas becas concentró a la "clase intelectual" en sus proyectos de investigación, desactivando políticamente a un amplio sector. Y a su vez, los partidos no han desarrollado una estrategia adecuada para allegarse a los intelectuales.

Por otro lado, la derecha está tratando de suprimir a los únicos medios de expresión de posiciones críticas. En este sentido, me interesa comentar lo que ha pasado con Dialéctica. En junio de 2015 se publicó el último número monográfico de Dialéctica, titulado "Adolfo Sánchez Vázquez. A cien años de su nacimiento (1915-2015)"38, y que contiene materiales que publiqué sobre el maestro desde que lo conocí y empecé a colaborar con él, primero como ayudante de la cátedra de Filosofía de la historia en la Facultad de Filosofía y Letras, luego como colaborador en la edición de la colección "Teoría y praxis" de la Editorial Grijalbo, y más tarde como colega y amigo. Después de la edición de este número, las autoridades de la BUAP nos comunicaron que la revista ya no contaría con el subsidio para su publicación. La Universidad fue hegemonizada por la izquierda en los setenta y ochenta, pero se tuvo que plegar a la política oficial de Carlos Salinas de Gortari cuando este asumió la Presidencia en 1988 y profundizó la política neoliberal. A pesar de ello, las autoridades de la Universidad siguieron patrocinando la revista. Sin embargo, en los últimos años el gobierno del Estado fue controlado por la derecha, el Partido de Acción Nacional (PAN) y la Universidad se ha plegado a esa orientación. Por cierto, tenemos excelentes colaboraciones por publicar, pero tenemos que ver qué se puede hacer en el futuro para mantener la publicación.

38 Dialéctica, Nueva época, año 39, Número 48, enero-junio 2015. 
Tu libro Más allá del derrumbe está atravesado por la pregunta y la preocupación sobre el futuro del socialismo y el marxismo en México, América Latina y el mundo. Teniendo en cuenta que ya han pasado más de veinticinco años de su publicación, ¿qué elementos del marxismo mantienen su vigencia y cuáles consideras que han perdido su utilidad teórica? ¿Cómo crees que se posicionó el marxismo frente a ese nuevo actor de la política mexicana que es el neozapatismo? Y más acá en el tiempo, ¿cómo se ubica frente al Movimiento de Regeneración Nacional (MORENA) y el "lopezobradorismo"?

Vayamos por partes. Sobre el marxismo, hay que distinguir entre el pensamiento de Marx y el marxismo. El pensamiento de Marx, a mi juicio, tiene una serie de proposiciones que continúan aún vigentes: la centralidad de la praxis y el hecho de que el hombre, a partir de sus necesidades, construye el mundo social y se constituye a sí mismo; la interrelación entre teoría y praxis, planteada en las "Tesis sobre Feuerbach"; y la concepción del marxismo como una filosofía de la praxis, como lo exponen Gramsci y Sánchez Vázquez. En un ensayo reciente, "Ética y política, de Adolfo Sánchez Vázquez", publicado en el libro colectivo Raíces en otra tierra. El legado de Adolfo Sánchez Vázquez ${ }^{39}$, consideré la necesidad de una nueva lectura de los dos autores que implique una complementariedad, entre otros aspectos. Por cierto, remito también a mí reciente libro titulado Marx y Freud: Hacia una nueva racionalidad de la sociedad y de la historia ${ }^{40}$, que escribí con Raúl Páramo Ortega y publiqué a fines de 2016. Considero que Marx definió las características esenciales del capitalismo y que en sus

\footnotetext{
39 Leyva Martínez, Gustavo, Pérez Cortés, Sergio, Rendón Alarcón, Jorge y Vargas Lozano, Gabriel (comps.), Raíces en otra tierra. El legado de Adolfo Sánchez Vázquez, Ciudad de México, Ediciones ERA, 2013.

40 Vargas Lozano, Gabriel y Páramo Ortega, Raúl, Marx y Freud: Hacia una nueva racionalidad de la sociedad y de la historia, Ciudad de México, Tirant lo Blanch-UAM-I, 2016.
}

transformaciones actuales se profundizan en un nivel que hubiera asombrado a Marx. De igual manera, pienso que se mantienen los temas de la ideología, de la enajenación, del fetichismo de la mercancía y también el tema del método empleado en El Capital.

Ahora bien, no se sería marxista en el sentido de Marx si no se toman en cuenta los problemas que han surgido en todos estos años: el tema del carácter destructivo de las fuerzas productivas y que origina la problemática de la crisis ecológica, que es central hoy en el desarrollo social, que, aunque planteado por Marx, no fue desarrollado; la problemática de la mujer está planteado en Marx y en Engels, pero que ha sido desarrollado hoy de manera importante por la filósofa alemana Frigga Haug y otras intelectuales; el tema de la influencia de las nuevas tecnologías, que es abordado por el filósofo Wolfgang Fritz Haug en su libro más reciente. Por cierto, yo tengo el honor de pertenecer al Diccionario histórico-crítico del marxismo, que se edita en Berlín y que lleva ocho volúmenes de mil páginas cada uno y que concentra una serie de trabajos de intelectuales de todo el mundo donde se abordan los problemas planteados por Marx y su evolución hasta el siglo XXI. Por ejemplo, el concepto de clases sociales, entre muchos otros. El Diccionario es una poderosa renovación del pensamiento de Marx desde la actualidad. Por su lado, Frigga Haug edita una Diccionario histórico-crítico del feminismo en donde aborda los temas de la mujer.

Un tema que no abordó suficientemente el marxismo en México es el del indigenismo. En esta dirección hay un estudio de Alberto Saladino sobre García Marxismo e indigenismo en México ${ }^{41}$ en donde aborda la temática. Yo creo que fue un enorme defecto del marxismo mexicano, y tal vez latinoamericano -salvo José Carlos Mariátegui en el Perú y otros autores-, el no tomar como centro la problemática de los pueblos originarios que hoy, gracias al

41 Saladino García, Alberto, Indigenismo y marxismo en América Latina, Toluca, UAEM, 1994. 
levantamiento zapatista de 1994, ha logrado tener una importante visibilidad. A mi juicio, en Chiapas, el Ejército Zapatista de Liberación Nacional (EZLN) ha conformado un laboratorio teórico-práctico que está dando sus frutos. El movimiento zapatista es un movimiento en pro de la justicia de los pueblos originarios, pero ello no quiere decir que no existan una serie de problemas que deben ser abordados, sobre todo, el tema de la unidad de la izquierda.

Sobre el "lopezobradorismo", considero que es un movimiento social progresista que se opone al neoliberalismo y lucha por la defensa de los intereses nacionales, aunque no es anticapitalista. Desde la constitución del Partido de la Revolución Democrática (PRD), el marxismo fue eliminado del movimiento político. La razón es que no querían "espantar a la burguesía", para decirlo coloquialmente, y llegar al poder mediante una posición socialdemócrata. Cárdenas se lanzó tres veces a la Presidencia de la República y el bloque en el poder no le permitió acceder a ella. Esa es una cuestión que no se ha reflexionado suficientemente y en este sentido creo que la izquierda no ha profundizado sobre los alcances y límites de la democracia liberal y, por el contrario, ha caído en sus trampas y contradicciones. Es por ello que a la práctica debe vincularse una buena reflexión teórica en donde un marxismo crítico y creador no puede estar ausente. Pero la parte teórica en nuestro país es muy débil porque en los últimos tiempos ha imperado un pragmatismo sin riberas. Vamos a ver que pasa en 2018 cuando se lleven a cabo las elecciones presidenciales. Hay que examinar con detalle lo que pasó en las recientes elecciones del Estado de México. Los ciudadanos debemos tener claro que se pretende hacer en concreto para salir de la crisis. La situación por la que atraviesa México es trágica y merece un cambio profundo al que se oponen las furias del narcotráfico, el imperio del norte, el grupo que ha detentado el poder durante muchos años y ha impuesto sus decisiones mediante fraudes electorales o golpes de Estado disfrazados, como el que llevó a cabo Salinas de Gortari frente a Cuauhtémoc Cárdenas en 1988. La izquierda tiene un reto formidable, pero, como siempre, se encuentra dividida.

Finalmente, con respecto al marxismo, podríamos decir que ha sido, en sus aspectos creativos y críticos una enorme aportación teórica. Pensemos en Ernst Boch y su reflexión sobre la utopía; los análisis sobre la historia de Eric Hobsbawm, E. P. Thompson o Pierre Vilar (por cierto, en Dialéctica publicamos una extraordinaria entrevista a Vilar hecha por un discípulo suyo ${ }^{42}$ ); la obra de Rosa Luxemburgo, Karel Kosik, Georg Lukács, Henri Lefebvre, Gramsci, Cerroni, Althusser (en lo que no se equivocó), Balibar, Mészáros, Schaff, Manuel Sacristán, Sánchez Vázquez, Bolívar Echeverría, etc., etc. No pueden barrer al marxismo -quienes pretendan hacerlo- debajo de la alfombra.

Para finalizar me gustaría preguntarte cómo imaginas que el marxismo debe enfrentar los tiempos de la inmediatez de las opiniones, propio de las redes sociales, de la digitalización y la virtualidad. 0 , dicho de otro modo: ¿cómo editar una revista marxista hoy?

Hoy debemos utilizar todos los recursos de las nuevas tecnologías para difundir nuestros mensajes. Me parece lamentable que no se hayan utilizado plenamente: las vías de podcast, de videos, de redes de comunicación, etc. Se organizan conferencias y no se tiene el cuidado de transmitirlas vía internet en tiempo real. Hay que aprovechar los recursos tecnológicos actuales para la difusión del pensamiento crítico.

Tenemos muchas tareas por delante: recuperar las grandes aportaciones del marxismo en muchas direcciones; actualizar sus planteamientos a partir de un conocimiento de la situación actual; caracterizar la revolución digital y evaluar lo positivo y negativo; defender a nuestros países de la superexplotación; combatir

\footnotetext{
42 Se refiere a "Tendencias actuales de la ciencia histórica en Francia y América Latina. Entrevista con Pierre Vilar", Dialéctica, Año III, Núm. 5, octubre 1978, pp. 129-146. En ese mismo número también se publicó "Historia social y filosofía de la historia", de Pierre Vilar.
} 
la enajenación; oponernos a la dependencia en todos sentidos; definir las líneas de la nueva sociedad que sustituirá a la ya obsoleta (en esta dirección, véase el libro de Anatole Anton y Richard Schmitt ${ }^{43}$ ); profundizar en las posibilidades del cambio social y tantas otras; pero, sobre todo, configurar las fuerzas que tendrán a su cargo la transformación de la sociedad.

Ciudad de México, 30 de junio de 2017 


\section{Bibliografía citada}

Altieri, Angelo, Cerroni, Umberto et al, Ideología, teoría y política en el pensamiento de Marx, Puebla, ICUAP 1980.

Anderson, Perry, “¿Existe una crisis del marxismo?”, Dialéctica, Año V, número 9, diciembre 1980, pp. 145-158.

Anton, Anatole y Schmitt, Richard, Hacia un nuevo socialismo, Barcelona, El Viejo Topo, 2011.

Aricó, José, Marx y América Latina, Buenos Aires, Catálogos, 1982.

Bayle, Mariana, "Arnaldo Córdova sobre la izquierda en los setenta", Nexos, 9 de febrero de 2015. "'México como escenario latinoamericano. Dictadura, revolución y democracia en la revistas Cuadernos Políticos (1974-1999)", Cuadernos del CEL, Vol. II, Núm. 3, pp. 300-314, 2017.

, "Revistas en combate'. Cultura, política y rupturas en la nueva izquierda mexicana

(1968-1875)', Cuadernos del CEL, Vol. II, Núm. 4, pp. 27-43, 2017.

Benjamin, Walter, Sobre el concepto de historia, Buenos Aires, Piedras de Papel, 2007.

Bidet, Jacques, "Panorama de revistas", Dictionnaire Marx Contemporain, París, PUF, 2001.

Burgos, Raúl, Los gramscianos argentinos. Cultura y política en la experiencia de Pasado y Presente, Buenos Aires, Siglo XXI, 2004.

Cabrera López, Patricia, Una inquietud de amanecer. Literatura y política en México, 1962-1987,

México, CEIICH-UNAM/Plaza y Valdez, [2005] 2007.

Carr, Barry, La izquierda mexicana a través del siglo XX, México, ERA, 1996.

Castañón, Adolfo, "Una historia personal de Vuelta", Saúl Susnowski (ed.), La cultura de un siglo. América Latina en sus revistas, Buenos Aires, Alianza, 1999, pp. 515-524.

Concheiro, Luciano, "Historia mínima de... El Machete", en Luciano Concheiro (coord.), El Machete (edición facsimilar), México, FCE/INAH/La Jaula Abierta, 2016, pp. XXVII-XLI.

Cortés, Martín, Un nuevo marxismo para América Latina. José Aricó: traductor, editor, intelectual,

Buenos Aires, Siglo XXI-CCC, 2015, pp. 52-64.

Del Barco, Oscar, Esbozo de una crítica a la teoría y práctica leninistas, Puebla, ICUAP, 1980.

Domínguez Michael, Christopher, "Las batallas políticas", Letras Libres, Número 96, diciembre 2006. "Relectura de El Machete", en Luciano Concheiro (coord.), El

Machete (edición facsimilar), México, FCE/INAH/La Jaula Abierta, 2016, pp. LV-LXIV.

Echeverría, Bolívar, 1995, "La ERA de Cuadernos Políticos", en Fernando Benítez (Ed.), AA. VV., Ediciones era 35 años. Neus Espresate. Guadalajara, Universidad de Guadalajara, 1995, pp. 35-40.

Florescano, Enrique, 2008, "Los orígenes", Nexos, enero 2008.

Gago, Verónica, Controversia: una lengua del exilio, Buenos Aires, Biblioteca Nacional, 2012.

García Vázquez, Xóchitl, "FEM, una mirada crítica al feminismo", Latinoamericano, Revista digital, número 6, pp. 36-40, marzo 2014.

Giller, Diego, "La revista de la derrota. Exilio y democracia en Controversia (1979-1981)", Latinoamérica. Revista de estudios latinoamericanos, año 13, n. 63, pp. 37-64, junio-diciembre 2016.

"Crítica de la razón marxista. 'Crisis del marxismo' en Controversia (1979-1981)", Revista Mexicana de Sociología, núm. 79, pp. 487-513, julio-septiembre 2017.

González, Horacio, "Pasado y Presente: la tragedia de los gramscianos argentinos", Revista Pasado y Presente. Tomo I. Primera época (1963-1965): edición facsimilar, Biblioteca Nacional, Buenos Aires, 2014, pp. 7-23.

Illades, Carlos, La inteligencia rebelde. La izquierda en el debate público en México, 2012.

Illades, Carlos, "El Machete en el debate comunista", Luciano Concheiro (coord.), El Machete (edición facsimilar), México, FCE/INAH/La Jaula Abierta, 2016, pp. XLV-L. 
Leyva Martínez, Gustavo, Pérez Cortés, Sergio, Rendón Alarcón, Jorge y Vargas Lozano, Gabriel (comps.), Raíces en otra tierra. El legado de Adolfo Sánchez Vázquez, Ciudad de México, Ediciones ERA, 2013.

López-Kijares, Antonio, La vida política de México y la revista Plural de Octavio Paz (1971-1976), México, ITAM.

Modonesi, Massimo, "Lecturas de las izquierdas mexicanas", Nueva Sociedad, n²68, marzo-abril, 2017, pp. 100-109, disponible en http://nuso.org/media/articles/downloads/6.TC Modonesi 268.pdf

Pacheco, Víctor Hugo, "1983: nace la revista Memoria", Memoria. Revista de Crítica Militante, número 253, Pág. 95, 2015.

Perales Contreras, Jaime, Vuelta, origen y desarrollo de una revista intelectual (1976-1986), México, ITAM, 1990.

Saladino García, Alberto, Indigenismo y marxismo en América Latina, Toluca, UAEM, 1994.

Sánchez Rebolledo, Adolfo, "Pensar el 68. Punto Crítico: Una historia de familia. Entrevista Con Adolfo Sánchez Rebolledo", Nexos, junio 1988

Vargas Lozano, Gabriel y Hernández Oramas, Roberto, "Veinticinco años de Dialéctica", Utopía y praxis latinoamericana, Año 6, Núm. 14, septiembre 2001, pp. 132-134.

Vargas Lozano, Gabriel y Páramo Ortega, Raúl, Marx y Freud: Hacia una nueva racionalidad de la sociedad y de la historia, Ciudad de México, Tirant lo Blanch-UAM-I, 2016.

Vargas Lozano, Gabriel, "Crónica de una elección anunciada", Dialéctica, Año VI, número 11, diciembre 1981, pp. 5-18. Más allá del derrumbe: Socialismo y democracia en la crisis de civilización europea, Ciudad de México, Siglo XXI, 1994.

Toluca, UAEM, 2007. Intervenciones filosóficas: ¿Qué hacer con la filosofía en América Latina?,

Vélez Pliego, Alfonso et. al., "Por una nueva alternativa para el pensamiento crítico", Dialéctica, Año 15, Número 21 (invierno), pp. 3-6, 1992.

Vilar, Pierre, "Tendencias actuales de la ciencia histórica en Francia y América Latina. Entrevista con Pierre Vilar", Dialéctica, Año III, Núm. 5, octubre 1978, pp. 129-146. 